\title{
DOI: 10.7596/taksad.v8i3.2248
}

Citation: Ivanov, A. V., Sagitova, V. R., \& Bolshakov, A. G. (2019). Phenomenon of Youth Street-Criminal Subculture in Russian Society. Journal of History Culture and Art Research, 8(3), 269-276. doi:http://dx.doi.org/10.7596/taksad.v8i3.2248

\section{Phenomenon of Youth Street-Criminal Subculture in Russian Society*}

\author{
Andrey Valeryevich Ivanov ${ }^{1}$, Victoria Ravil'evna Sagitova², Andrey Georgievich Bolshakov ${ }^{3}$
}

\begin{abstract}
This article is devoted to AUE, a street subculture on social media and in cities. The term AUE in Russian translates as "prisoners' ways are united", or "prisoners' criminal union". It is a subculture that promotes a criminal way of life, cultivates an image of a hooligan, and is based on hatred towards law enforcement. However, there is a certain stylization in all of that, especially when AUE manifests on Russian social media. Members are aged between 12-13 years and 25-30 years; there are older members as well. The goal of this study is to perform a comprehensive analysis of collective stereotypes about crime and prison that exist among the street youth. The phenomenon of AUE is viewed as a hierarchy of finance and power that solves the social problems that the youth faces. Financial and legal help may be provided to prisoners "from the street". It also creates youth financial institutions such as a shared cash fund and a system for financial and physical support. The article lists popular paradigms about crime and prison, and social practices of the street youth. This article also discusses the social and psychological features of AUE members by creating a generalized portrait of an AUE member. We also determine the degree of hostility of this movement to the state and society. Finally, we identify youth groups that may be targeted by the destructive AUE ideology.
\end{abstract}

Keywords: Youth, Subculture, Masculinity, Xenophobia, Social media, Crime, Extremism.

\footnotetext{
* This study was funded by a grant of the Russian Fund of Fundamental Research, project No. 19-01131376 opn in Kazan Federal University.

${ }^{1}$ Kazan Federal University, Institute of Social and Philosophical Sciences and Mass Communications. E-mail: Berserk2004@yandex.ru

2 Kazan Federal University, Institute of Social and Philosophical Sciences and Mass Communications. E-mail: mega.sppa@mail.ru

3 Kazan Federal University, Institute of Social and Philosophical Sciences and Mass Communications. E-mail: mega.sppa@mail.ru
} 


\section{Introduction}

Scientific studies have compared the extent of social damage to economic characteristics, and have found that social damage alone has no relation to economic crises, and that the flow of urbanized living and conflicting norms has a greater impact on the emergence of antisocial diseases, and sometimes Some teens will have to break laws and regulations in the age of speed and technology. Seeing such a situation forced the First World countries to make changes to the law as appropriate. Amendments that rejected the penalties and proposed setting up juvenile delinquency courts. A court with jurisdiction to deal with juvenile and juvenile offenses with the purpose of educating, educating and reforming juveniles and children. Sociologists see the survival of societies in the next generation and believe that the survival of societies depends on their upbringing and social life, and they consider children to be the concrete example of the next generation, but the same sociologists believe that if a child's personality does not follow the right path of socialization. And it will interfere with the acceptance of social norms and values, and later it will be impossible for even the social reformers to recover, and the mental and physical problems of these people will be entrenched in the communities. Street children are seen as eyewitnesses to the injury, and the child escapes from the home, the child escapes from social and family contexts. But this escape sounds an alarm that the weaknesses and failures in the system of supportive institutions, especially welfare schools and families, are occurring.

One of the issues that have attracted the attention of psychologists and sociologists is the spread of delinquents on the streets among children and adolescents. Various hypotheses have been put forward by experts on this increase, some referring to the specifics of civilized societies, who believe that the increasing speed to move toward industrial development, crime and criminality has led to increased crime. They are seen as the product of the weakness of religious and religious beliefs and say that the spread of science has had no result other than humanism, neglect, alienation, and has kept the man away from human development and perfection.

Modern Russian youth faces various antisocial projects, extremist doctrines and destructive subcultures and ideologies in virtual space and in real life. One of the destructive platforms, primarily on social media, is the AUE ideology.

The term AUE in Russian translates as "prisoners' ways are united", or "prisoners' criminal union". It is a subculture that promotes a criminal way of life, cultivates an image of a hooligan, and is based on hatred towards law enforcement. However, there is a certain stylization in all of that, especially when AUE manifests on Russian social media.

Criminal and anti-social youth groups are created when ordinary street groups are criminalized and influenced by the ideology of the criminal world.

The goal of this study is to perform a comprehensive analysis of collective stereotypes about crime and prison that exist among the street youth in Russia.

This study was completed by combining quantitative and qualitative methods, such as monitoring AUE communities on the VK social network for membership growth and by conducting in-depth interviews with AUE members. Overall, 15 groups on the VK social network were monitored by our tools. We have conducted twenty interviews with AUE members and activists. Interviews were held in Kazan, Naberezhnye 
Chelny, Almetyevsk and Buinsk. AUE community members are aged between 12-13 years and 25-30 years; there are older members as well.

The names of AUE communities on social media include the abbreviation AUE, as well as words such as "vagabond", "hooligan", "hoodlums", "blokes", "fellows", "bandits", "thief" [Blatnaya, et al, 2019]. These VK groups range from two hundred thousand members to two thousand members and less [Cohen, A. 1955]. In contemporary Russia, the popularity of criminal subculture among the youth reached a threatening scale and can potentially disrupt proper social and economic development of the country. We observe an increasingly strong influence of the criminal world on masculine youth street communities. However, the AUE youth subculture is not a look-alike of the traditional criminal subculture [Erikson, E. 1994].

The youth who share the AUE philosophy sometimes create myths about the origins of the movement, an idealized view of the male honor, mutual aid, and an image of honorable young men who "watch over the neighborhood".

The tipping point for an adolescent is the graduation from the 9th form of the secondary school. Most students face the issue of deciding their career and whether they should go to a college, vocational school, or to a high school and then to a university, as well as the issue of further socialization among their peers. During that time, teenage children are most vulnerable socially and physically, especially those who received incomplete secondary education [Ivanov, \& Kozlov, 2019].

\section{Methods}

As part of this study, we have created an explanatory model for the AUE phenomenon. We demonstrate the influence of the criminal street ideology on the choice of strategy of participation in destructive street communities by Russian youth. Communications outside of the street community are most often aggressive.

As E. Erikson states, youth can "absorb an identity so deep only by way of aggression, and sometimes outbursts of violence..., and elements of a previously negative identity become dominant, while positive elements are eliminated completely" [Karl Mannheim, 1995].

The authors based this article on sociological and criminological studies of the criminal subculture by such researchers as A. Cohen [Katin, 2007], R. Merton [Merton, R. 1957], T. Sellin [Patsansky Padik 2019]. Thus, R. Merton proposed a concept of social anomy, within which we can study marginalized communities that create a specific subculture that is close to a criminal subculture. A. Cohen noted a special type of culture characteristic of criminal societies that is created as a result of cultural conflict. We have based our study of the AUE phenomenon on the methodologies of these authors.

Young people get involved in the AUE ideology through communication in the streets and at school, as well as on social media, primarily on VK. Young people learn about the AUE ideology through masculine street practices while spending time with elder peers.

A teenage life passes within three key platforms: home, school, and the street. The street is the space where masculine criminal practices may become a part of the youth life, involve young people into street 
communities, or pit them against such subcultures. The notion of the "street" is used by members of this movement and by competing youth subcultures, primarily by "the right".

A street youth subculture is characterized by a combination of expansion and aggressive collectivist values to regulate the street space and contrast themselves to traditional universal human norms of life [Sellin,1938].

The street youth typically holds immature political views, lacks established models for participating in politics and active social life, and is dominated by "the ideological unconscious" or quasi-ideologies. According to K. Mannheim, "the word "ideology" implies the understanding that in some situations, the collective unconscious of certain groups hides the actual state of the society from themselves and from others". In this case, the lack of social lifts for such young people creates a situation where the values and mechanisms of socialization into adulthood may not always follow a scenario approved by the society [Shpak, 2012; Soleymani, et al, 2014; Shatilova et al, 2018].

\section{Results and Discussion}

The social and psychological "street" personality type (such as a member of the AUE community) can be divided into two categories: a "prison guy" and a "street guy".

A "prison guy" is a young man who is sent to prison after already having been introduced to the AUE ideology, and who returns to "the street" after serving his sentence.

The second category, "street guys" (who may potentially move to the first category), are divided into several age groups: the young, the senior, the ancient. Age groups are not strictly defined. The "street guys" mainly try to distance themselves from the AUE topic on social media, but it would be wrong to believe that they completely ignore this part of the virtual subculture. Our analysis of personal pages of "street guys" of Kazan shows that they usually subscribe to street-related and criminal-related groups, or create their own private communities on social media where they talk to other people from their street. The "street guys" try to maintain a certain anonymity and do not announce their district to persons who are not involved with street subculture traditions, and certainly do not talk about that with law enforcement.

AUE-related groups do not impose a complete ban on alcohol and tobacco, and the opposition to these vices is optional. Most interviewees are neutral about drinking and smoking, or support bans for minors.

They have a neutral attitude to non-criminal related tattoos, whereas they believe that criminal-themed tattoos should only be acquired by those who have a criminal record. They prefer the types of sports that do not require a systematic commitment (pullup bars, football) or go to a gym with a group.

A "street guy" is a teenager or a young man who is looking for psychological protection and physical support in a masculine community where collectivism and group interaction removes the issue of an individual's vulnerability. Some young people join AUE communities by obtaining their membership and favorable attitude through financial donations, but they are at the lowest level of the hierarchy. For others, the street space is a way to assert themselves, especially over weaker peers or younger men. We should also note the issues of mobility and the ability to quickly assemble to resolve street conflicts or commit crime. 
A common theme in most interviews was the fact that they feel powerful and mighty only in their street community. A lack of physical support and assistance during street conflicts prompts a "street guy" to mobilize members of their own AUE community. These teenagers are capable of individual aggression if they face an obviously weak victim who is made to look guilty in the eyes of the attacker using dialog and special "street questions"; this removes the barrier that the attack against such a victim is unjustified.

On the periphery of the AUE subculture are the "virtual AUE members" who, once infected with the criminal ideology, may "join the streets". Typically, these are students aged 12 to 16 , who came across the AUE subculture in the vicinity of their home. The young men joining AUE are not necessarily from dysfunctional families. An important situation occurs when a family for some reason is not involved in the child's socialization process, and he spends time by himself and there is no control over his activities. Interviewees did not fully agree on the definition of "the street" and "AUE". A teenager may share the ideas of AUE, but he has to be accepted into the street. There are certain criteria, and the street as a collective masculine entity decides whether the person is suitable.

Of importance for a "virtual AUE member" are criminal and hooligan themed videos and photos. It cannot be oversimplified and reduced to pictures of expensive cars, beautiful ladies, weapons, fight dogs and other attributes of a successful criminal life. There are images that elicit an emotional response from a broad audience, for example, an image of a mother waiting for her vagabond son, and so on. Thus, members of the AUE-themed groups and other interested readers are influenced through a host of psychological tools.

\section{Summary}

The internal life of an AUE community is strictly regulated; there are rules of communication with people inside the group and with those who are not from "the street"; the community has their own pastime activities. A high degree of collectivism is typical for AUE communities. They use the notion of a "family", which is interpreted as the close circle of "guys" a person communicates with, or, more broadly, one's entire "street". The street subculture often uses the phrase "I live with them", which is understood as being a member of an AUE street brotherhood.

AUE subculture members can be roughly divided into the following groups:

1. "virtual AUE members" - outer periphery of the subculture, which may "move to the street" once they are infected with criminal ideology;

2. "street guys" (who may potentially move to the third category) who are divided into several age groups: the young, the senior, the ancient. Age groups are not strictly defined;

3. A "prison guy" is a young man who is sent to prison after already having been introduced to the AUE ideology, and who returns to "the street" after serving his sentence.

Separately, we identify a group of people with a criminal record who have a negative attitude towards AUE and do not believe it is related to the criminal culture.

Thus, the AUE subculture becomes a mutual criminalization factor in the street space. Because of the AUE phenomenon, a hierarchy of finance and power arises that solves the social problems that the youth faces. Financial and legal help may be provided to prisoners "from the street". It also creates youth financial 
institutions such as a shared cash fund (similar to the shared cash funds of the criminal world) and a system for financial and physical support.

Most importantly, these communities promote primarily destructive world views:

First, strong hatred towards state institutions, through promoting enmity towards law enforcement. Through the use of memes on social media, readers are prepared for open confrontation and attacks on the police.

Second, isolation from the constructive mechanisms and socialization in the non-street world that can only be used for taking advantage of it. In other words, AUE creates an image of a private subculture for those who are "in", leading to a philosophy of aggressive distancing and an attitude of using society for its benefits but not giving back (working is taboo, earning easy money without effort, etc.).

Criminal ideals are promoted as part of group communication in the street space, as well as in the virtual space through criminal photo and video content.

In this case, the AUE subculture in Russia can be understood as a tool of criminal organizations for recruiting the youth into criminal activities as "infantry" that can be used for shows of power.

In order to understand the negative processes among the youth, it is important to further monitor destructive movements that tend to grow into street activism, e.g. into planned illegal political activities or serial criminal hooliganism to terrorize the population.

\section{Conclusions}

Deviation and violation of norms have always existed throughout human history. Breaking social order and deviation from norms rarely happened in small and elementary societies, and tribes and tribes adhered to social norms based on community traditions and customs. But in today's societies, due to the extreme social and geographical mobility, cultural cohesion is low and ethical agreement is rarely observed. Mass media reports and scientific research show that breaking social order and deviating from society's norms in cities, especially large cities, has not only declined but also increased as technology and industry have progressed.

Youth must be described as a transition from early adulthood. A group of writers and social commentators see youth as a transition from a state of dependence to a state of complete independence and development that enables one to fulfill the rights and obligations of adulthood. Like other periods of life, youth is a social structure that changes with time. More precisely, youth must be analyzed based on the structural and cultural characteristics of a society. Therefore, youth is different in every society and in every period of its history.

Laws and social institutions have defined youth to some extent. Because these laws and institutions consider some of the tasks and conditions of society as tasks and conditions of society as specific and compulsory. For example, the end of compulsory education, the minimum age for marriage, the right age for duty, the minimum age for a driver's license, etc. are all based on specific laws and part of the social structure of youth. At the same time, youth is a situation that is used in different social arenas. 
When a parent or one of them is a perpetrator or perpetrator of morality, the family has a direct and indirect effect on children and adolescents. This influence comes primarily from two sources: one is learning violence during domestic violence and the other acquiring delinquency by imitating one or both of them.

The number of criminals who have found a certain anti-social formation in their original family is small. In most cases, the family plays an indirect role in one's tendency to commit crimes. The family environment, although not morally healthy, that is, the parents of the offender can have a definite effect on the formation of the offender's personality, provided the family does not at least provide the child with the necessary love and upbringing to become the norm.

Therefore, these communities promote primarily destructive world views: xenophobia and hatred towards other social groups that are different from AUE members. These groups are usually denied masculinity and honor; they are categorized as losers who are essentially not human and can be victimized, robbed and even murdered. It creates a situation of social inequality and a strict hierarchy with the "rightful guys" being above the average citizens who are considered to be "losers" and "lowlife". The underclass in a society like that is the "room devils" or "losers" who are unable to protect themselves. This philosophy usually leads to people asserting themselves by humiliating the weak, in order to feel a sense of superiority.

The similarity of AUE and ultraradical political organizations in their anti-government ideas (hatred towards law enforcement) and the preparedness for crime; both are potentially prepared for mass street hooliganism.

\section{Acknowledgments}

The work is performed according to the Russian Government Program of Competitive Growth of Kazan Federal University.

\section{References}

Cohen, A. (1955). Delinqent Boys. New York.

Erikson, E. (1994). Identity: Youth and Crisis. New York: W.W. Norton, cop., p. 79.

Ivanov, A. V. \& Kozlov, V. E. (2019). The phenomenon of the AUE criminal street subculture in the Republic of Tatarstan. Kazan Teaching Journal, pp. 205-208.

Karl Mannheim, (1995). Ideologie und Utopie. Klostermann, p. 302.

Katin, V. I. (2007). Criminal romanticism as a cultural phenomenon in contemporary Russia: author's abstract of the culturology thesis. - Saratov, - P. 8.

Merton, R. (1957). Social Theory and Social Structure. New York, The Free Press.

Sellin, T. (1938). Culture Conflict and Crime. N.Y.: Social Science Reseach Council. 
Shpak, S. V. (2012). Criminal subculture of the youth in the contemporary Russian society: development and propagation trends: Author's abstract of the philosophy thesis: 09.00.11 - Krasnodar. P.8.

Soleymani, M., Nezhadali, L. H., \& Mohammad, B. Z. (2014). Effective indicators in Bank customer satisfaction, UCT Journal of Social Sciences and Humanities Research, 2(1): 1-7.

Shatilova, L. M., Borisova, V. V., \& Kasatkina, O. A. (2018). Representation of the linguistic and cultural concept "lie" in the French and Russian language picture of the world. Opción, 34(85-2), 257-276.

* Blatnaya Khata * Shpana米Kriminal *.u.e. * [electronic resource]. - Accessed at: https://vk.com/aye_blatxata-Accessed on 10 June 2019

Patsansky Padik [electronic resource]. - Accessed at: https://vk.com/to_boys - Accessed on 10 June 2019 